\title{
Interface Structure of Cu Wire Bonding on Cu Substrate with Sn Plating
}

\author{
Shinichi Fujiwara ${ }^{1, *}$ and Reinhold H. Dauskardt ${ }^{2}$ \\ ${ }^{1}$ Yokohama Research Laboratory, Hitachi, Ltd., Yokohama 244-0817, Japan \\ ${ }^{2}$ Stanford University, Stanford, CA 94305-4034, USA
}

\begin{abstract}
In previous research on copper wire bonding on a copper substrate with tin plating, suitable thickness and binding conditions for the tin plating were chosen using the peel test after the copper wire bonding. These conditions were determined to be a thickness of 10 microns, a stage temperature of $373 \mathrm{~K}$, a bonding power of 500 to $700 \mathrm{~mW}$ and a bonding time of 30 to $50 \mathrm{~ms}$. Cross-sectional observations of the bonding interface indicated that the tin layer remained between the copper wire and copper substrate after bonding under these conditions. The purpose of the present study was to evaluate the joint interface structure of the bonded copper wire on the copper substrate with the tin plating. Residual Sn exists locally at the initial bonding interface, and the locations bonded to the interstitial $\mathrm{Sn}$ are intermixed with the locations where the $\mathrm{Cu}$ wire is bonded to a $\mathrm{Cu}-\mathrm{Sn}$ intermetallic compound. No oxide film layer was found at the bonding interface in the joint between the $\mathrm{Cu}$ wire and $\mathrm{Cu}-\mathrm{Sn}$ intermetallic compound; TEM images indicated that these have metallic bonding in which $\mathrm{Cu}$ and $\mathrm{Cu}_{3} \mathrm{Sn}$ are directly bonded. This is in contrast to ultrasonic bonding between $\mathrm{Cu}$ and $\mathrm{Sn}$, wherein the $\mathrm{Cu}$ and $\mathrm{Sn}$ are bonded by means of the $\mathrm{Sn}$ oxide film.

[doi:10.2320/matertrans.MB201203]
\end{abstract}

(Received June 1, 2012; Accepted August 16, 2012; Published November 25, 2012)

Keywords: wire bonding, interface structure, semiconductor device packaging, intermetallic compound, joint reliability, ultrasonic bonding

\section{Introduction}

Wire bonding has long been used for connecting the electrodes of semiconductor devices to external terminals, and currently remains the mainstream method for this purpose. Gold $(\mathrm{Au})$ wires are most often used because they are easy to work with and exhibit superior corrosion resistance; they have been extensively investigated. ${ }^{1,2}$ Meanwhile, pad pitches continue to decrease and by 2018, the minimum pad pitch is expected to be $30 \mu \mathrm{m}$ and the minimum wire diameter $\left.12.5 \mu \mathrm{m} .{ }^{3}\right)$ However, because bonding reliability decreases when $\mathrm{Au}$ reacts with the $\mathrm{Al}$ used for wiring in semiconductor devices, ${ }^{4)}$ and neck breaks can occur, increasing cost, as wire diameters become finer. Thus selecting a material to replace $\mathrm{Au}$ is a crucial problem. $\mathrm{Ag}, \mathrm{Al}$ and $\mathrm{Cu}$ are being studied as a replacement for $\mathrm{Au}{ }^{5-8}$ ) of these, $\mathrm{Cu}$ is probably the strongest candidate for future finer pitch applications due to its superior thermal and electrical conductivity, and its strength against neck breaks. However, $\mathrm{Cu}$ is difficult to form into uniform balls for ball bonding since it readily forms an oxide film in air. $\mathrm{Cu}$ also requires greater power during bonding since it is more difficult to deform compared to Au.

In the current research, we conducted a study of wedge bonding wherein wires are directly bonded without forming a $\mathrm{Cu}$ ball. In addition, $\mathrm{Cu}$, which is widely used as the wiring material for substrates and leads, was selected as the material for the electrodes and external terminals to which the $\mathrm{Cu}$ wire was bonded, and the bondability of $\mathrm{Cu}$ wire to $\mathrm{Cu}$ substrates was evaluated. $\mathrm{Cu}$ wire bonding to $\mathrm{Cu}$ substrates has been previously studied; however surface oxidation of $\mathrm{Cu}$ remains a concern. ${ }^{9-11)}$ In previous investigations, ${ }^{12)}$ the $\mathrm{Cu}$ wires were bonded after suppressing the formation of oxide films on $\mathrm{Cu}$ by Sn-plating the $\mathrm{Cu}$ substrate, and parameters for bonding the $\mathrm{Cu}$ wire to the $\mathrm{Cu}$ substrate but leaving residual $\mathrm{Sn}$ at the joint interface were derived. In this study, the joint cross sections were

*Corresponding author, E-mail: shinichi.fujiwara.mf@hitachi.com examined in detail by scanning electron microscopy (SEM) and transmission electron microscopy (TEM) to understand the bonding state after initial bonding.

\section{Experimental Procedure}

\subsection{Initial bonding test and bonding state}

A manual wire ultrasonic bonding device was used in this research. The ultrasound frequency was $63 \mathrm{kHz}$, the bonding load range was 0.17 to $0.88 \mathrm{~N}$, and the bonding power and ultrasound application time were arbitrarily set. The $\mathrm{Cu}$ wire used in this research had $99.99 \%$ purity, showed 8 to $16 \%$ elongation, and $0.12 \mathrm{~N}$ breaking load. The wire diameter was $25 \mu \mathrm{m}$.

A Cu substrate, C1020R type, with $10-\mu$ m-thick Sn plating was secured on a hotplate with the Sn-plated side up. $\mathrm{Cu}$ wire bonding was performed after cleaning the Sn-plated surface with alcohol. The bonding load was fixed at $0.5 \mathrm{~N}$, and the temperature of the hotplate was set to $373 \mathrm{~K}$ for $60 \mathrm{~s}$. The $\mathrm{Sn}$-plated $\mathrm{Cu}$ substrate used in this work formed a $\mathrm{Cu}-\mathrm{Sn}$ intermetallic compound before bonding.

Previous research suggested that good bonding could be achieved by heating a $\mathrm{Cu}$ substrate with a $10-\mu \mathrm{m}$-thick $\mathrm{Sn}$ plating to $373 \mathrm{~K}$ at a bonding power of 500 to $700 \mathrm{~mW}$ for 30 to $50 \mathrm{~ms}{ }^{12)}$ The joint strength was found to be approximately $0.05 \mathrm{~N}$. From this result, the initial bonding state and longterm reliability were evaluated for bonding at $500 \mathrm{~mW}$ for $30 \mathrm{~ms}$, which allowed high joint strength to be achieved in a short time.

Wire surface conditions were observed by SEM from a 52 degree tilted view of the bonded wire. The bonding states were subsequently observed using focused ion beam (FIB) milling to prepare a cross section in the vertical direction relative to the bonding surface.

\subsection{TEM observation of the $\mathrm{Cu}$ wire/ $\mathrm{Sn} / \mathrm{Cu}$ bonding interfaces}

A Hitachi FIB milling system and a dual beam FIB/SEM (FEI) system were used to prepare TEM samples. A field 


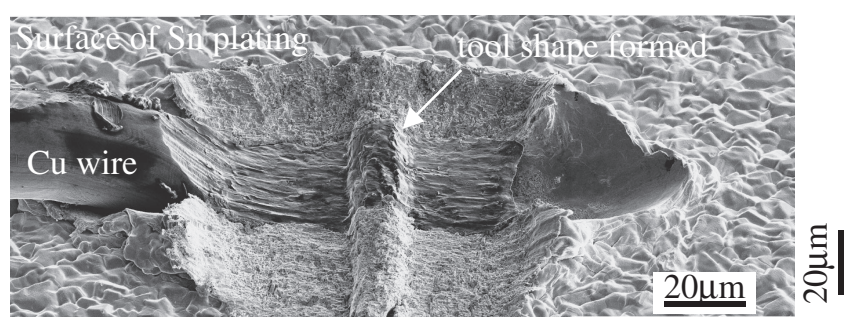

Fig. 1 SEM image of $\mathrm{Cu}$ wire bonding (52 degree tilted).

emission transmission electron microscope (JEOL Ltd.) was used for the TEM observations at an acceleration voltage of $200 \mathrm{kV}$. Thin film samples of the $\mathrm{Cu}$ wire/Sn plating/Cu substrate joint face were prepared by FIB for TEM. Electron beam diameter of TEM analysis is $1 \mathrm{~nm}$.

\section{Results and Discussion}

\subsection{Understanding the initial bonding state}

Figure 1 shows a photograph of the $\mathrm{Cu}$ wire bonded to an Sn plating, as viewed from a 52 degree tilt angle. The direction of the ultrasonic waves is from left to right. It can be seen that the ultrasonic application removes $\mathrm{Sn}$ toward the tip of the wire; the part of the wire touched by the tool is formed to the shape of the tool tip. Although no elongation is seen in the direction of the impression in the places modeled by the tool recess, the $\mathrm{Cu}$ is elongated in the impression direction in other places. Thus, we assume that with this tool shape, the $\mathrm{Cu}$ wire is restrained by the recess in the tool tip, but the $\mathrm{Cu}$ wire slides on the $\mathrm{Sn}$ plating contact surface.

Figure 2 shows the initial $\mathrm{Cu}$ wire/ $\mathrm{Sn}$ plating/Cu substrate joint interface. As previously discussed, we discovered that this is a mixture of regions where the $\mathrm{Cu}$ wire and $\mathrm{Cu}$ substrate are bonded only by the $\mathrm{Cu}-\mathrm{Sn}$ intermetallic compound and regions where they are bonded by the $\mathrm{Cu}-\mathrm{Sn}$ intermetallic compound and $\mathrm{Sn}$. In order to be able to classify this bonding as bonding between the $\mathrm{Cu}$ wire and $\mathrm{Cu}-\mathrm{Sn}$ intermetallic compound or bonding between the $\mathrm{Cu}$ wire and $\mathrm{Sn}$, we subjected each joint interface to detailed observations using TEM. We first investigated the bonding state between the $\mathrm{Cu}$ wire and $\mathrm{Cu}-\mathrm{Sn}$ intermetallic compound.

Figure 3 shows observations in the vicinity of the joint at a location bonded only with the $\mathrm{Cu}-\mathrm{Sn}$ intermetallic compound; some types of cavities were locally found at the $\mathrm{Cu}$ wire $/ \mathrm{Cu}-\mathrm{Sn}$ intermetallic compound interface and the $\mathrm{Cu}-\mathrm{Sn}$ intermetallic compound/Cu substrate interface. Only one kind of cavity was present at the $\mathrm{Cu}$ wire/Cu-Sn intermetallic compound boundary located at the crystal grain boundaries, as shown in Fig. 4. It is conjectured that these were missed during the FIB processing (called 'lacked grain'). In addition, other cavities seen along the bonding surface are thought to be non-attached regions where the $\mathrm{Cu}$ wire and $\mathrm{Cu}-\mathrm{Sn}$ intermetallic compound were unable to bond during the ultrasonic bonding (called 'gaps'). Meanwhile, since the $\mathrm{Cu}-\mathrm{Sn}$ intermetallic compound/Cu substrate interface is formed before the ultrasonic bonding, it is assumed that the cavities, termed 'voids', found at this interface do not originate in the ultrasonic bonding. These voids were formed

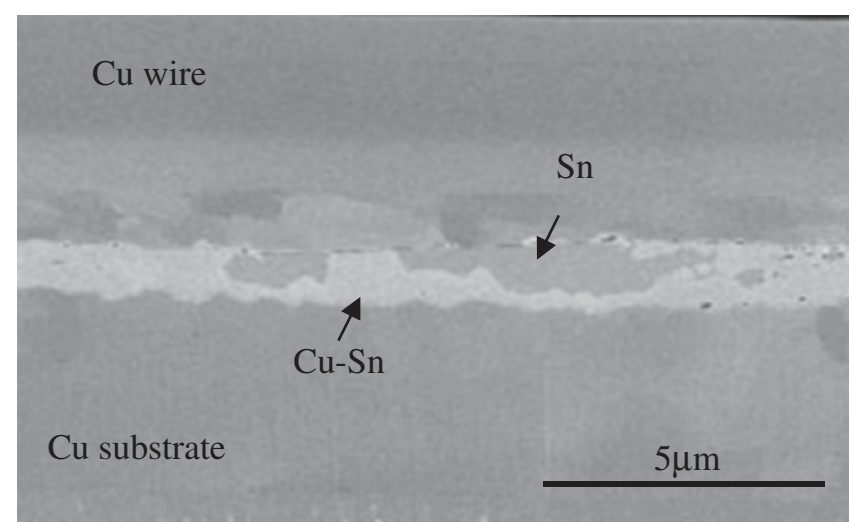

Fig. 2 The cross-section result of SEM observation of the initial $\mathrm{Cu}$ wire/ $\mathrm{Sn}$ plating/ $\mathrm{Cu}$ substrate joint interface.

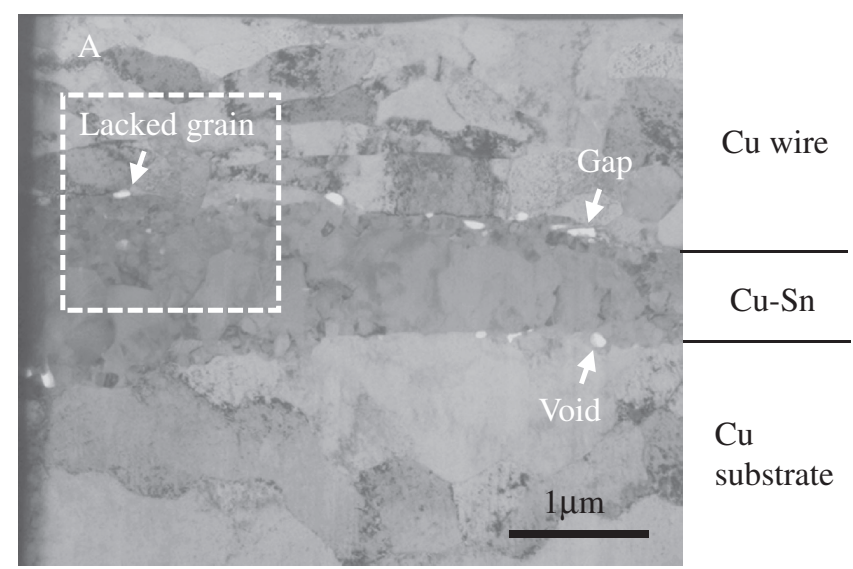

Fig. 3 The observation view in the vicinity of the joint at a location bonded only by the $\mathrm{Cu}-\mathrm{Sn}$ intermetallic compound.

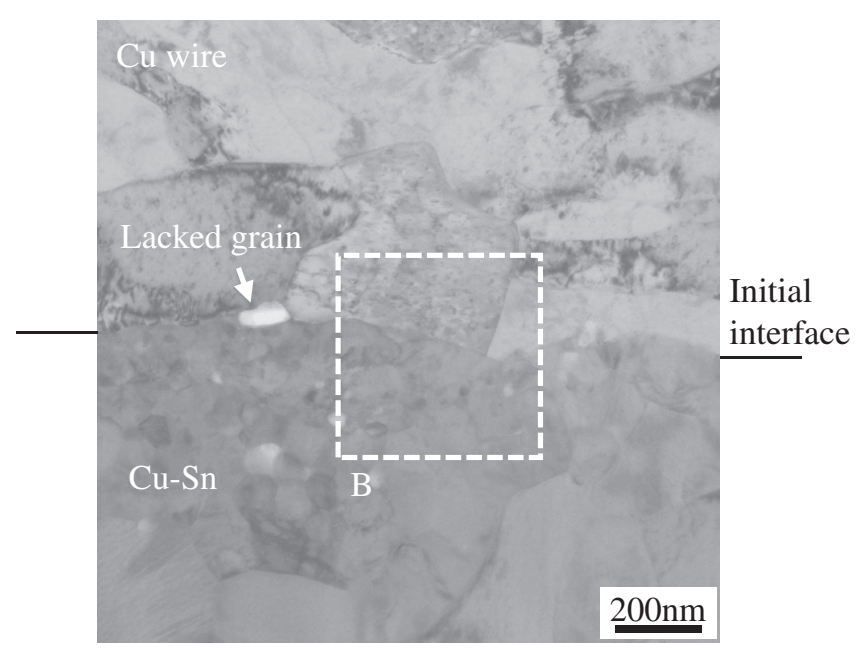

Fig. 4 The result of TEM observation between $\mathrm{Cu}$ wire and $\mathrm{Cu}-\mathrm{Sn}$ intermetallic compound (region A in Fig. 3).

before the ultrasonic bonding because the tin plating process was reflow plating with heating. ${ }^{12)}$

Figures 5, 6 and 7 show the results of observations of the $\mathrm{Cu}$ wire/Cu-Sn intermetallic compound interfaces. The crystal grains of the $\mathrm{Cu}-\mathrm{Sn}$ intermetallic compound are small at the bonding interface between the $\mathrm{Cu}$ wire and $\mathrm{Cu}-\mathrm{Sn}$ intermetallic compound, as shown in Fig. 5. Considering that 


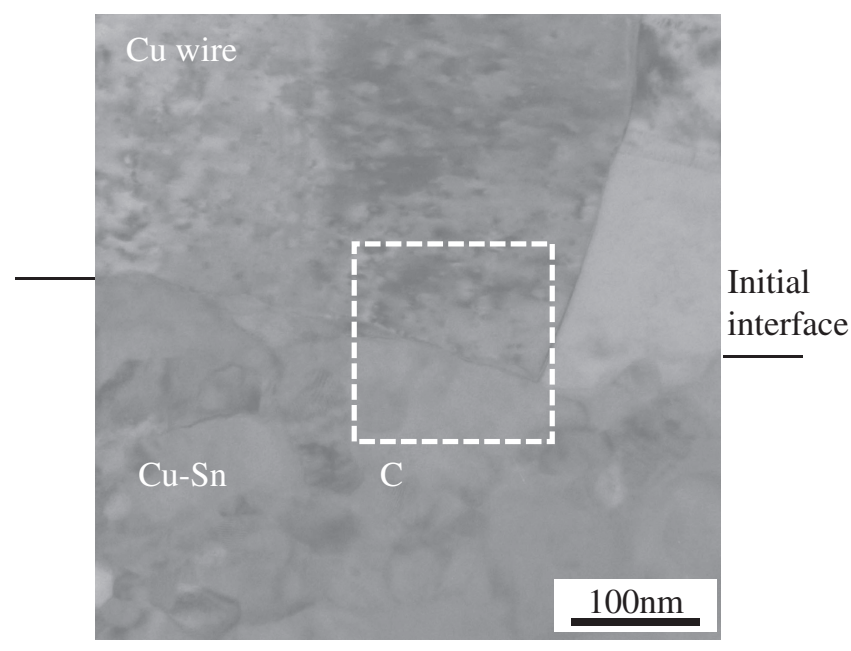

Fig. 5 The result of TEM observation between $\mathrm{Cu}$ wire and $\mathrm{Cu}-\mathrm{Sn}$ intermetallic compound (region B in Fig. 4).

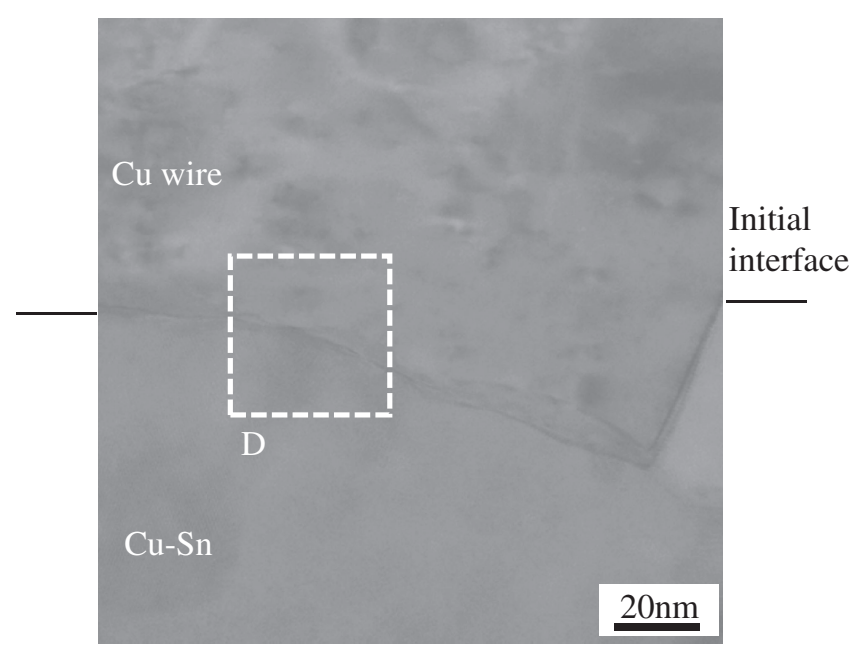

Fig. 6 The result of TEM observation between $\mathrm{Cu}$ wire and $\mathrm{Cu}-\mathrm{Sn}$ intermetallic compound (region $\mathrm{C}$ in Fig. 5).

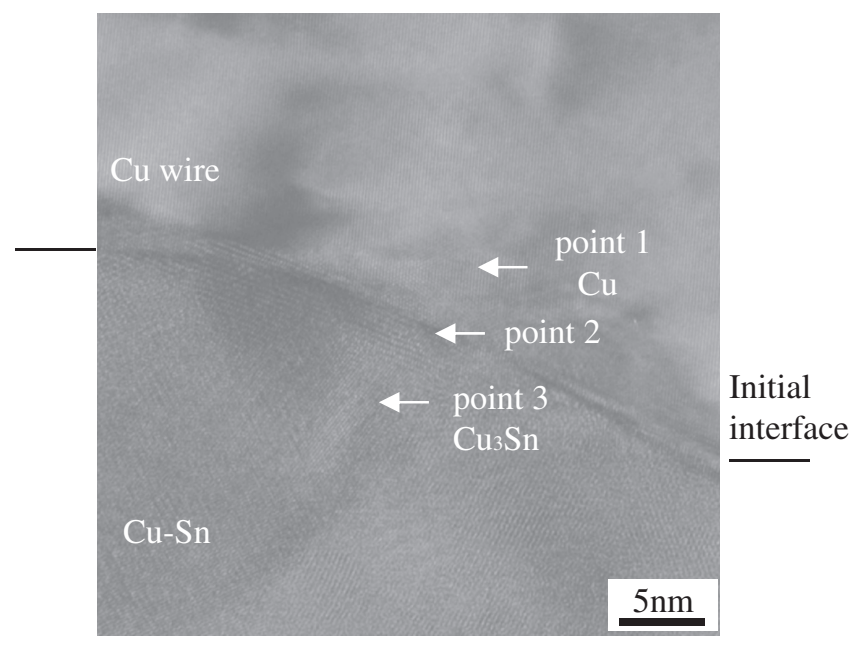

Fig. 7 The result of TEM observation between $\mathrm{Cu}$ wire and $\mathrm{Cu}-\mathrm{Sn}$ intermetallic compound (region D in Fig. 6).

$\mathrm{Sn}$ was present on the $\mathrm{Cu}-\mathrm{Sn}$ intermetallic compound before introducing the ultrasound, it is considered that the $\mathrm{Cu}-\mathrm{Sn}$ was nucleated during the growth process of the $\mathrm{Cu}-\mathrm{Sn}$
Table 1 Analysis data by EDX on spots 1 to 3 (Fig. 7).

\begin{tabular}{ccc}
\hline Analysis point & Cu ratio $(\mathrm{mol} \%)$ & Sn ratio $(\mathrm{mol} \%)$ \\
\hline 1 & 100.0 & 0 \\
2 & 90.0 & 10.0 \\
3 & 75.8 & 24.2 \\
\hline
\end{tabular}

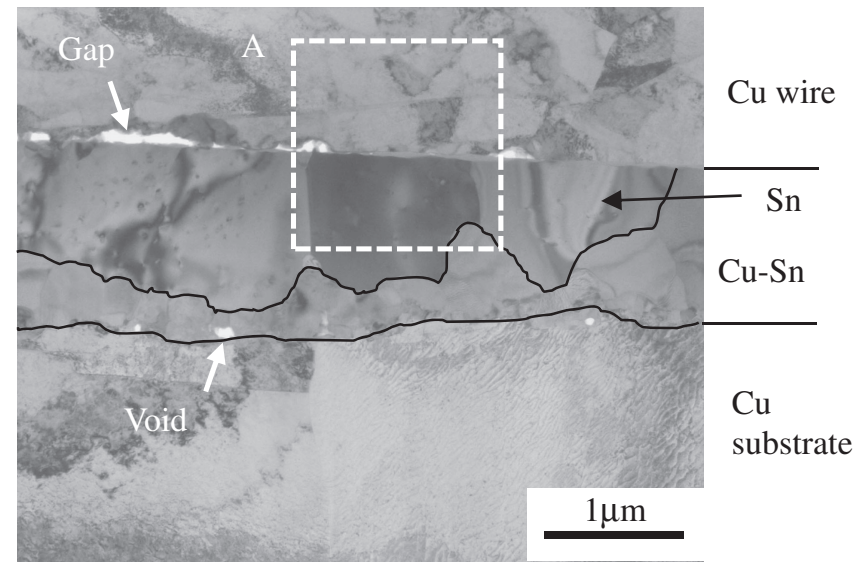

Fig. 8 The TEM observation result for the area of the $\mathrm{Cu}$ wire/Sn bonding and the $\mathrm{Cu}$ wire/ $\mathrm{Cu}-\mathrm{Sn}$ intermetallic compound bonding in the mixture.

intermetallic compound. The results of quantitative analysis of the $\mathrm{Cu}$ wire $/ \mathrm{Cu}-\mathrm{Sn}$ intermetallic compound interface are shown in Table 1, and it is known that metallic bonding is accomplished at the bonding interface without the presence of oxide films of either $\mathrm{Cu}$ or $\mathrm{Sn}$. It was also confirmed that the $\mathrm{Cu}-\mathrm{Sn}$ intermetallic compound at the bonding interface is $\mathrm{Cu}_{3} \mathrm{Sn}$. It is apparent from the above discussion that bonding at the $\mathrm{Cu} / \mathrm{Cu}-\mathrm{Sn}$ intermetallic compound interface is metallic bonding of $\mathrm{Cu}$ and $\mathrm{Cu}_{3} \mathrm{Sn}$.

\section{2 $\mathrm{Cu}$ wire/Cu-Sn intermetallic compound bonding state}

Observations for the areas of $\mathrm{Cu}$ wire/Sn bonding and $\mathrm{Cu}$ wire/Cu-Sn intermetallic compound bonding are shown in Fig. 8. The lines in Fig. 8 show the $\mathrm{Sn} / \mathrm{Cu}-\mathrm{Sn}$ intermetallic compound interface and the $\mathrm{Cu}-\mathrm{Sn}$ intermetallic compound/ $\mathrm{Cu}$ substrate interface. According to Fig. 8, the majority of $\mathrm{Sn}$ crystal grains are $1 \mu \mathrm{m}$ or greater in diameter, but the grains of the $\mathrm{Cu}-\mathrm{Sn}$ intermetallic compound are less than $1 \mu \mathrm{m}$ in diameter, and the grain sizes are even finer, especially in the vicinity of the boundary with the $\mathrm{Cu}$ substrate. This is thought to be because the $\mathrm{Cu}-\mathrm{Sn}$ grains become finer as the $\mathrm{Cu}-\mathrm{Sn}$ intermetallic compound grows. In addition, gaps are seen at the interface between the $\mathrm{Cu}$ wire and Sn (upper left side of Fig. 8), because the shapes of the gaps follow the interface, and an approximately $10 \mathrm{~nm}$ layer was seen on the Sn-side of the gap; there is high probability that this is an area that did not attach during the ultrasonic bonding.

Figures 9 and 10 show the expanded views of a $\mathrm{Cu}$ wire/ Sn interface joint where a gap could not be confirmed. It was discovered from Fig. 9 that bonding between the $\mathrm{Cu}$ wire and $\mathrm{Sn}$ was accomplished with a thin intervening layer, the thickness of which was found to be approximately 10 to 


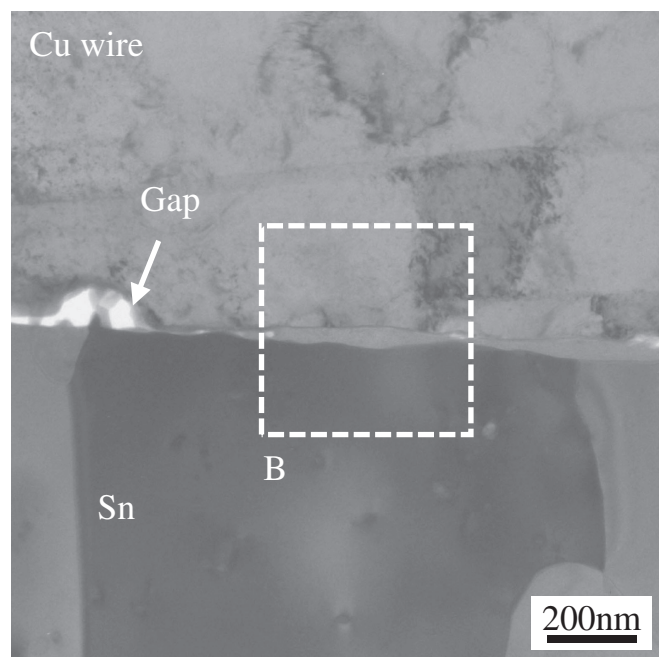

Fig. 9 The result of TEM observation between $\mathrm{Cu}$ wire and $\mathrm{Sn}$ (region A in Fig. 8).

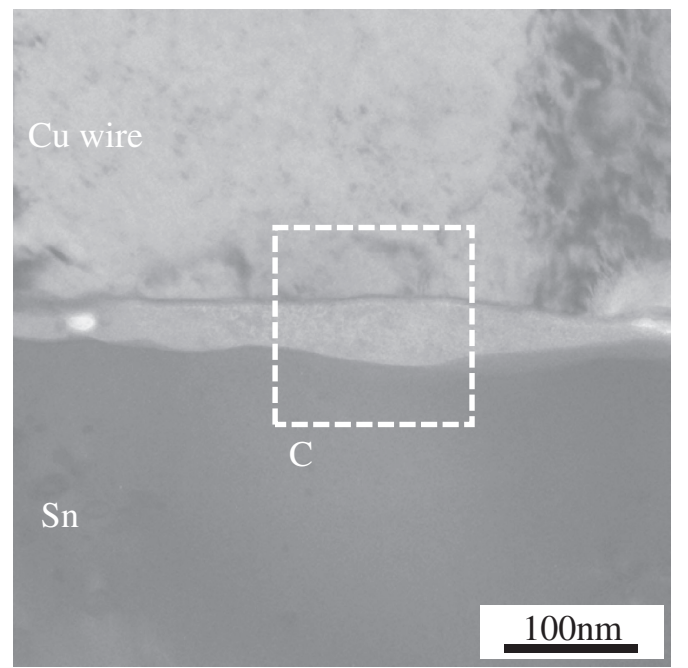

Fig. 10 The result of TEM observation between $\mathrm{Cu}$ wire and $\mathrm{Sn}$ (region $\mathrm{B}$ in Fig. 9).

$80 \mathrm{~nm}$ from Fig. 10. Quantitative analysis was performed at the location shown in Fig. 11 to identify this layer. The analysis results are shown in Table 2. According to Table 2, $\mathrm{Sn}, \mathrm{O}$ and $\mathrm{Cu}$ were confirmed from analysis point 2 , where an oxide of $\mathrm{Sn}$ or $\mathrm{Cu}$ formed in a layer. From this, it became apparent that the $\mathrm{Cu}$ wire and $\mathrm{Sn}$ were bonded by means of the oxide film.

In ultrasonic bonding, the intermetallic bonding is believed to be accomplished by mechanically eliminating the oxide films formed on the surfaces of the bodies being bonded by ultrasound and compression, and bringing into contact the fresh metallic surfaces exposed. However, our current observations indicate that $\mathrm{Cu}$ and $\mathrm{Sn}$ were bonded by the oxide film. Lattice images of the various bonding surfaces were observed to confirm the $\mathrm{Cu}$ wire/Sn oxide film and the Sn oxide film/Sn bonding states (Fig. 12, Fig. 13).

A distinct $\mathrm{Cu}$ crystal lattice on the $\mathrm{Cu}$ wire side was observed at the $\mathrm{Cu}$ wire/Sn oxide film interface (Fig. 12). The crystal lattice in the Sn oxide film was also observed, however, the long-range order of the crystal lattice was not as

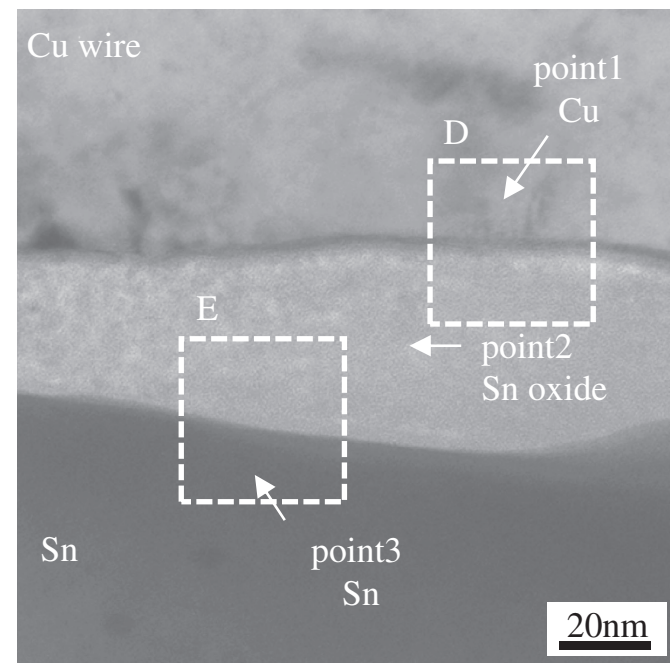

Fig. 11 The result of TEM observation between $\mathrm{Cu}$ wire and $\mathrm{Sn}$ (region $\mathrm{C}$ in Fig. 10).

Table 2 Analysis data by EDX on spots 1 to 3 (Fig. 11).

\begin{tabular}{cccc}
\hline Analysis point & $\mathrm{O}$ ratio $(\mathrm{mol} \%)$ & $\mathrm{Cu}$ ratio $(\mathrm{mol} \%)$ & $\mathrm{Sn} \mathrm{ratio}(\mathrm{mol} \%)$ \\
\hline 1 & 0 & 100.0 & 0 \\
2 & 41.2 & 9.5 & 49.3 \\
3 & 0 & 0 & 100.0 \\
\hline
\end{tabular}

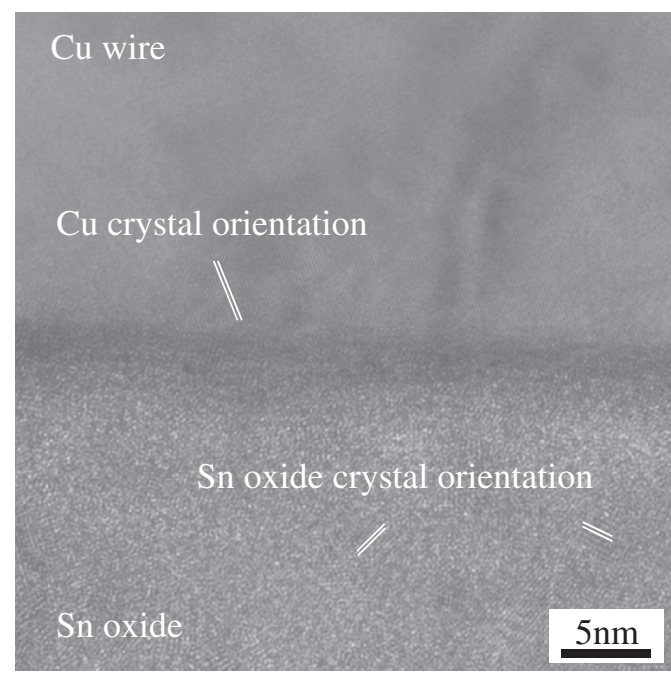

Fig. 12 The result of TEM observation between $\mathrm{Cu}$ wire and $\mathrm{Sn}$ (region $\mathrm{D}$ in Fig. 11).

long as that on the $\mathrm{Cu}$ wire side, and the lattice fringes were confirmed in multiple directions. There were a $3 \mathrm{~nm}$ widths layer in the vicinity of the bonding interface, but clear lattice fringe could not be confirmed, and it was found that the $\mathrm{Cu}$ wire and Sn oxide film were bonded without any defects such as cavities. It is assumed that the $\mathrm{Cu}$ wire and $\mathrm{Sn}$ oxide film were bonded at the bonding interface by the oxygen in the oxide film.

In the lattice image observations at the $\mathrm{Sn}$ oxide film/Sn interface (Fig. 13), lattice fringes were seen in multiple directions in the Sn oxide film, but no long-range order of 


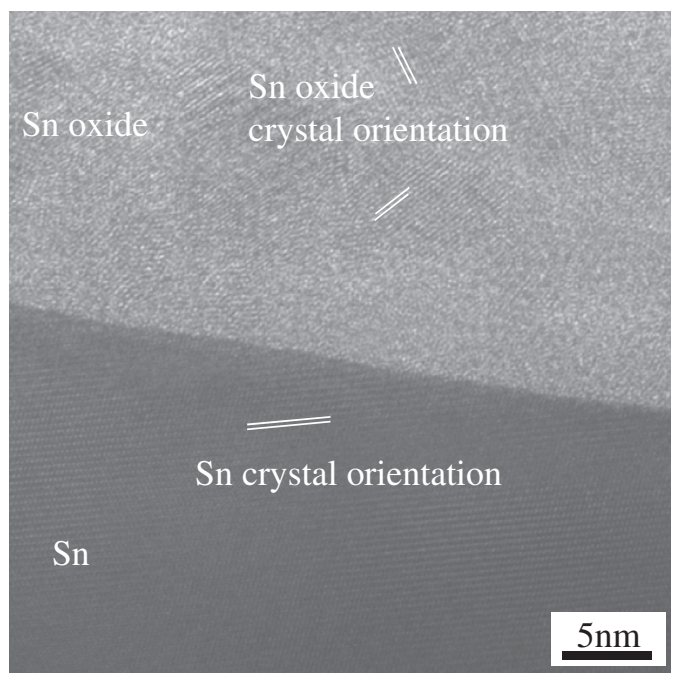

Fig. 13 The result of TEM observation between $\mathrm{Cu}$ wire and $\mathrm{Sn}$ (region $\mathrm{E}$ in Fig. 11)

any kind was observed. However, a Sn crystal lattice could be distinctly confirmed on the Sn side, and continuity was found to be high. In addition, unlike in the interface between the $\mathrm{Cu}$ wire and the $\mathrm{Sn}$ oxide film, no areas of contrast could be confirmed, nor were any cavities found in the vicinity of the interface. This is thought to be due to the differences in the bonding mechanism between the Sn oxide film and $\mathrm{Sn}$ and the bonding mechanism between the $\mathrm{Cu}$ wire and $\mathrm{Sn}$ oxide film. This $\mathrm{Sn}$ oxide film was formed by leaving the $\mathrm{Sn}$ exposed to air in the sample preparation process. Therefore, we assume that bonding at the interface between the Sn oxide film and the $\mathrm{Sn}$ as seen in Fig. 13 is due to bonding by oxygen, as in common metal oxide films. In addition, since this interface is formed without adding any external energy, it is thought that the $\mathrm{Sn}$ oxide film/Sn interface can also be distinctly confirmed. However, we assume that the areas of contrast were formed by forced bonding, since the interface between the $\mathrm{Cu}$ wire and $\mathrm{Sn}$ oxide film was formed by the ultrasound energy and compression during bonding.

In this investigation, we thus discovered that metals and oxide films could be locally bonded by ultrasonic bonding of $\mathrm{Cu}$ wire and $\mathrm{Sn}$ oxide film.

\subsection{Bonding state at $\mathrm{Cu}$ wire/Sn interface}

Figure 14 shows SEM observation of the joint crosssection after peel testing of the $\mathrm{Cu}$ wires bonded at $500 \mathrm{~mW}$ for $30 \mathrm{~ms}$. This joint is the remaining joint at one end of a wire that was subjected to a peel test at $0.05 \mathrm{~N}$, the other joint having been ruptured. From Fig. 14, it can be seen that though there were local $\mathrm{Sn}$ regions, the $\mathrm{Cu}$ wire was bonded to a $\mathrm{Cu}-\mathrm{Sn}$ intermetallic compound. In addition, voids were seen at the interface between the $\mathrm{Cu}-\mathrm{Sn}$ intermetallic compound and the $\mathrm{Cu}$ substrate, and cracks that developed in the peel test had advanced into the interface between the $\mathrm{Cu}-\mathrm{Sn}$ intermetallic compound and $\mathrm{Cu}$ wire or into the $\mathrm{Sn}$.

Consequently, we were able to confirm that for $\mathrm{Cu}$ wire bonded to the $\mathrm{Sn}$-plated $\mathrm{Cu}$ under these bonding conditions, residual Sn was locally present at the bonding interface

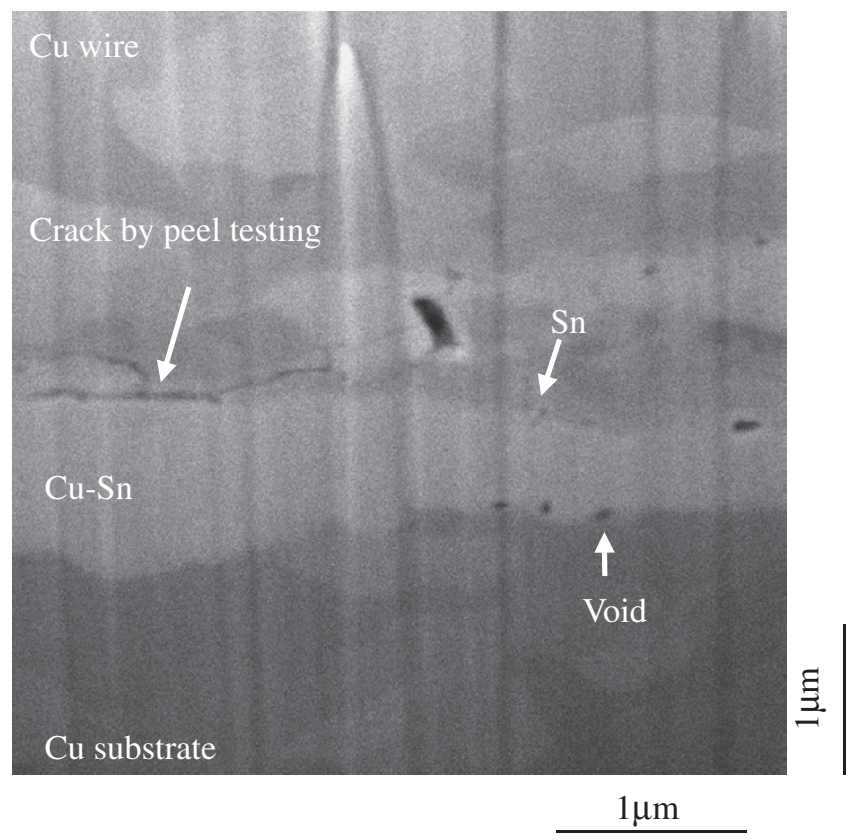

Fig. 14 The result of SEM observation of the joint cross section after peel testing of $\mathrm{Cu}$ wires bonded at $500 \mathrm{~mW}$ for $30 \mathrm{~ms}$ (52 degee tilted).

between the wire and $\mathrm{Cu}$ substrate, and bonding took place between the wire and the $\mathrm{Cu}-\mathrm{Sn}$ intermetallic compound.

\section{Conclusion}

The following conclusions were obtained with regard to the $\mathrm{Cu}$ wire bonding to a Sn-plated $\mathrm{Cu}$ substrate.

(1) Residual $\mathrm{Sn}$ exists locally at the initial bonding interface, and the locations bonded with interstitial $\mathrm{Sn}$ are intermixed with locations where the $\mathrm{Cu}$ wire is bonded with the $\mathrm{Cu}-\mathrm{Sn}$ intermetallic compound.

(2) No oxide film layer was found at the bonding interface in the joint between the $\mathrm{Cu}$ wire and the $\mathrm{Cu}-\mathrm{Sn}$ intermetallic compound, which TEM lattice images showed to be metallic bonding with $\mathrm{Cu}$ and $\mathrm{Cu}_{3} \mathrm{Sn}$ being directly bonded.

(3) At locations where there was residual $\mathrm{Sn}$, the $\mathrm{Cu}$ wire and $\mathrm{Sn}$ were bonded with an interstitial $\mathrm{Sn}$ oxide film, and there was a bonding area of indistinct crystal orientation of approximately $3 \mathrm{~nm}$ at the interface between the $\mathrm{Cu}$ wire and $\mathrm{Sn}$ oxide film.

(4) In ultrasonic bonding between $\mathrm{Cu}$ and $\mathrm{Sn}$, the bonding was formed by the Sn oxide film.

\section{Acknowledgments}

The authors wish to thank Dr. M. S. Oliver, Dr. A. W. Hsing and Dr. T. S. Kim of Stanford University for their support in making specimens.

\section{REFERENCES}

1) D. Y. Shinand and P. J. Ficalora: IEEE Trans. Electron. Dev. 26 (1979) 27-34.

2) S. Y. Yang, H. J. Byun, S. W. Park and W. J. Lee: Proc. 45th Annual on IEEE Reliability Physics Symposium, (2007) pp. 113-116. 
3) H. S. Chang, K. C. Hsieh, T. Martens and A. Yang: IEEE Trans. Compon. Packag. Tech. 27 (2004) 155-160.

4) K. Toyozawa, K. Fujita, S. Minamide and T. Maeda: IEEE Trans. Compon. Hybrids Manuf. Tech. 13 (1990) 667-672.

5) J. Schwizer, M. Mayer, D. Bolliger, O. Paul and H. Baltes: The 24th IEEE/CPMT Symposium on Electronics Manufacturing Technology Symposium, (Austin, USA, 1999) pp. 108-114.

6) S. Koyama, M. Takahashi and K. Ikeuchi: Solid State Ion. 172 (2004) $397-401$

7) M. Onishi and H. Fujibuchi: Trans. Jpn. Inst. Met. 16 (1975) 539548
8) I. Shohji, T. Sakurai and S. Arai: Key Eng. Mater. 297-300 (2005) 2819-2824.

9) H. Xu, C. Liu, V. V. Silberschmidt and H. Wang: The 58th Electronic Components and Technology Conference, (Florida, USA, 2008) pp. 1424-1430.

10) H. Clauberg, B. Chylak, N. Wong, J. Yeung and E. Milke: IEEE CPMT Symposium Japan, (Tokyo, Japan, 2010) pp. 1-4.

11) M. Maeda, T. Sato, N. Inoue, D. Yagi and Y. Takahashi: Microelectron. Reliab. 51 (2011) 130-136.

12) S. Fujiwara and R. H. Dauskardt: Q. J. Japan Weld. Soc. 28 (2010) 362-368. 